Research Article

\title{
Toward Respiratory Support of Critically Ill COVID-19 Patients Using Repurposed Kidney Hollow Fiber Membrane Dialysers to Oxygenate the Blood
}

\author{
David M. Rubin $\mathbb{D}^{1},{ }^{1}$ Neil T. Stacey, ${ }^{2}$ Tonderayi Matambo, ${ }^{3}$ Claudia Do Vale,,${ }^{4,5}$ \\ Martin J. Sussman, ${ }^{6}$ Tracy Snyman, ${ }^{7,8}$ Mervyn Mer, ${ }^{9,10}$ and Diane Hildebrandt ${ }^{3}$ \\ ${ }^{1}$ Biomedical Engineering Research Group, School of Electrical and Information Engineering, University of the Witwatersrand, \\ Johannesburg, South Africa \\ ${ }^{2}$ School of Chemical and Metallurgical Engineering, University of the Witwatersrand, Johannesburg, South Africa \\ ${ }^{3}$ Institute for the Development of Energy for African Sustainability, University of South Africa (UNISA), Florida, South Africa \\ ${ }^{4}$ Morningside Hospital, Johannesburg, South Africa \\ ${ }^{5}$ Department of Medicine, Division of Nephrology, University of the Witwatersrand, Johannesburg, South Africa \\ ${ }^{6}$ Cardio-thoracic Surgery, Milpark Hospital, Johannesburg, South Africa \\ ${ }^{7}$ Department of Chemical Pathology, University of the Witwatersrand, Johannesburg, South Africa \\ ${ }^{8}$ National Health Laboratory Service, Johannesburg, South Africa \\ ${ }^{9}$ Charlotte Maxeke Johannesburg Academic Hospital, Johannesburg, South Africa \\ ${ }^{10}$ Department of Medicine, Divisions of Critical Care and Pulmonology, University of the Witwatersrand, \\ Johannesburg, South Africa
}

Correspondence should be addressed to David M. Rubin; david.rubin@wits.ac.za

Received 3 August 2020; Accepted 22 September 2020; Published 3 November 2020

Academic Editor: Antonio Gloria

Copyright (c) 2020 David M. Rubin et al. This is an open access article distributed under the Creative Commons Attribution License, which permits unrestricted use, distribution, and reproduction in any medium, provided the original work is properly cited.

\begin{abstract}
The COVID-19 pandemic has highlighted resource constraints in respiratory support. The oxygen transfer characteristics of a specific hollow fiber membrane dialyser was investigated with a view to repurposing the device as a low-cost, readily available blood oxygenator. Oxygen transfer in a low-flux hollow fiber dialyser with a polysulfone membrane was studied by passing first water and then blood through the dialyser in countercurrent to high-purity oxygen. Oxygen transfer rates of about $15 \%$ of the nominal $250 \mathrm{ml}$ (STP)/min of a typical adult oxygen consumption rate were achieved for blood flow rates of $500 \mathrm{ml} / \mathrm{min}$. Using two such dialysis devices in parallel could provide up to $30 \%$ of the nominal oxygen consumption. Specific hollow fiber dialysis devices operating with suitable pumps in a veno-venous access configuration could provide a cost-effective and readily available supplementation of respiratory support in the face of severe resource constraints.
\end{abstract}

\section{Introduction}

The COVID-19 pandemic has highlighted resource constraints in the management of respiratory distress [1], and debate continues on the merits of ventilation vs. less invasive respiratory support for COVID-19, in terms of disease management and safety of medical staff [2]. Extracorporeal membrane oxygenators (ECMOs) have been used successfully to oxygenate and decarbonate blood $[3,4]$, and there are a number of indications for the use of ECMO [5]. However, its use is costly and resource intensive [6].

Our objective is not to replace ECMO but rather to investigate repurposing of renal hollow fiber membrane dialysers (HFMDs) as cost-effective augmentation of respiratory support in resource-constrained environments.

Unlike purpose-designed ECMO membranes [7, 8], renal dialysis membranes are designed for liquid-liquid transfer of specific molecules. Nonetheless, their existing 
clinical approval for renal replacement therapy makes repurposing HFMDs as oxygenators an attractive option.

Nominal $\mathrm{O}_{2}$ consumption in adults is approximately $250 \mathrm{ml} \cdot \mathrm{min}^{-1}(\mathrm{STP})\left(0.357 \mathrm{~g} \cdot \mathrm{min}^{-1}\right)$ [9]. The purpose of respiratory support is to achieve concentrations of $\mathrm{O}_{2}$ and $\mathrm{CO}_{2}$ in arterial blood that are compatible with proper organ function. Repurposed dialysers could potentially provide sufficient gas transfer to compensate for the respiratory deficit in some patients.

We investigated $\mathrm{O}_{2}$ transfer in a renal HFMD using water as a blood substitute. This facilitated exclusion of problems such as air bubble formation and transmembrane fluid leakage. The minimum $\mathrm{O}_{2}$ transfer rate in water motivated further experiments with blood.

\section{Materials and Methods}

\subsection{Theoretical Considerations and Computational} Methodology. Mass transfer in the HFMD is modelled by the following equation:

$$
k_{0} A=\frac{q \mathrm{O}_{2}}{L M \Delta \mathrm{pO}_{2}},
$$

where $k_{0}$ is the mass transfer coefficient, $A$ is the membrane area, $q \mathrm{O}_{2}$ is the rate of oxygen transferred, and $L M \Delta \mathrm{pO}_{2}$ is the logarithmic mean of partial pressure differences at the top and bottom of the device.

Defining the partial pressure difference between the blood inlet and the oxygen flow outlet as $\Delta \mathrm{pO}_{2}^{\text {top }}$ and between the blood outlet and oxygen flow inlet as $\Delta \mathrm{pO}_{2}^{\text {bottom }}$, and expanding the definition of logarithm mean, the expression for the product of the mass transfer coefficient and the area $\left(k_{0} A\right)$ becomes

$$
k_{0} A=\frac{q \mathrm{O}_{2}}{\left(\Delta \mathrm{pO}_{2}^{\text {top }}-\Delta \mathrm{pO}_{2}^{\text {bottom }}\right) / \ln \left(\Delta \mathrm{pO}_{2}^{\text {top }} / \Delta \mathrm{pO}_{2}^{\text {bottom }}\right)} \text {. }
$$

To achieve a given $q \mathrm{O}_{2}$, this equation facilitates determination of the minimum $k_{0} A$ of the device.

As oxygen transport capacity of blood resides primarily in haemoglobin, it reaches saturation at a low partial pressure of oxygen. Thus, we can assume that oxygen transfer into blood takes place within a narrow range of partial pressures. Also, for high-purity oxygen, the $\mathrm{pO}_{2}$ may be regarded as essentially constant.

The oxygen-carrying capacity of blood is $8800 \mu \mathrm{M}$ of $\mathrm{O}_{2}$ bound to the $\mathrm{Hb}$ for $100 \%$ saturation [10] and dissolved $\mathrm{O}_{2}$ in blood is negligible. The HFMD cartridges are designed for blood flow rates up to $500 \mathrm{ml} / \mathrm{min}$, and we evaluate oxygencarrying capacity of blood for an $\mathrm{Hb}$ concentration of $15 \mathrm{~g} /$ $100 \mathrm{ml}$ and a typical oxyhaemoglobin dissociation curve.

At sea level atmospheric pressure, and for a typical venous and arterial $\mathrm{pO}_{2}$ of 6 and $12.7 \mathrm{kPa}$ (and corresponding $\mathrm{HbSat}$ of $45 \%$ and $95 \%$ ), respectively, the oxygen uptake in $500 \mathrm{ml}$ of blood and the $\Delta \mathrm{pO}_{2}^{\text {top }}$ and $\Delta \mathrm{pO}_{2}^{\text {bottom }}$ are calculated and substituted into (2) to estimate the required $k_{0} A$. This is repeated for an inlet venous HbSat of $25 \%$ as shown in Table 1.
It is assumed that mass transfer across the membrane is rate limiting rather than mass transfer through blood or the reaction of oxygen with haemoglobin.

2.2. Materials and Methods for Gas Transfer into Water. The experiments were conducted at the Biotechnology Laboratory at UNISA, Johannesburg, at an altitude of about $1700 \mathrm{~m}$ with atmospheric pressure about $84 \mathrm{kPa}$ and temperature about $25^{\circ} \mathrm{C}$.

A low-flux Leoceed-21N (Asahi Kasei Medical) hollow fiber membrane renal dialyser cartridge was used in this study. The polysulfone membrane has an effective surface area of $2.1 \mathrm{~m}^{2}$, and the HFMD has a priming volume of $108 \mathrm{ml}$ and an internal fiber diameter and wall thickness of $185 \mu \mathrm{m}$ and $35 \mu \mathrm{m}$, respectively. The manufacturer-specified maximum blood flow rate is $500 \mathrm{ml} \cdot \mathrm{min}^{-1}$ (mean residence time about $13 \mathrm{~s}$ at this flow rate). Maximum transmembrane pressure (TMP) is rated at $80 \mathrm{kPa}$.

Tap water was deoxygenated by boiling and allowed to cool in a sealed glass bottle and measured for dissolved oxygen (SD 400 OXI L, Lovibond, Amesbury, UK). The deoxygenated water was pumped through the vertically mounted HFMD using a peristaltic pump (Qdos Chemical Metering Pumps, Watson Marlow, Cornwell, UK) via the blood inlet at 50, 200, and $500 \mathrm{ml} \cdot \mathrm{min}^{-1}$ and discharged into a beaker covered with parafilm to minimize oxygen losses.

High-purity (>99\%) oxygen (Afrox Gas, Johannesburg, South Africa) was passed countercurrent through the HFMD via the dialysate inlet, using a pressure regulator set between 60 and $80 \mathrm{kPa}$ (gauge) followed by a needle valve to control flow rate at $400 \mathrm{ml} \cdot \mathrm{min}^{-1}$.

2.3. Materials and Methods for Gas Transfer into Blood. This study with human blood was approved by the Institutional Review Board of the South African National Blood Service (SANBS) Human Research Ethics Committee (certificate number: 2019/0521) and the Institutional Review Board of the University of the Witwatersrand, Johannesburg Human Research Ethics Committee (Medical) (certificate number: M200456). The experiments were conducted at the Chemical Pathology Laboratory, University of the Witwatersrand, Johannesburg, at an altitude of about $1500 \mathrm{~m}$ (atmospheric pressure about $85 \mathrm{kPa}$ ).

Recently expired donor whole blood (SANBS) was warmed in a water bath at $37^{\circ} \mathrm{C}$ and pooled in a glass flask to constitute approximately 4.51 to which approximately 3000 units of heparin (heparin sodium mucosal, Fresenius Kabi, $5 \mathrm{ml}$ of $1000 \cdot \mathrm{U} / \mathrm{ml}$ ) was added.

Nitrogen sparge gas was bubbled through the blood to reduce the \% oxygen saturation of haemoglobin (HbSat) to typical venous levels [11]. The nitrogen flow was gradually increased from $11 / \mathrm{min}$ until froth was visualized.

As shown in Figure 1, blood was pumped by a roller pump through the hollow fibers of a vertically mounted HFMD, from top to bottom, at $500 \mathrm{ml} / \mathrm{min}$. The upstream placement of the roller pump reduces the risk of red blood cell lysis prior to oxygenation. Blood was discharged into a 
TABLE 1: Theoretical calculated maximum oxygen uptake per $500 \mathrm{ml}$ of blood and required $k_{0} A$ for specified inlet conditions where the outlet is near saturation with $\mathrm{pO}_{2}$ of $95 \mathrm{~mm} \mathrm{Hg}$.

\begin{tabular}{lcr}
\hline Inlet $\mathrm{pO}_{2}(\mathrm{~mm} \mathrm{Hg})(\mathrm{HbSat})$ & $\mathrm{Max} \mathrm{O}_{2}$ uptake $(\mathrm{mg} / 500 \mathrm{ml} \mathrm{blood})$ & $k_{0} A\left(\mathrm{mg} \cdot \mathrm{min}^{-1} \cdot \mathrm{kPa}^{-1}\right)$ \\
\hline $45(76 \%)$ & 35.7 & 0.389 \\
$25(45 \%)$ & 73.4 & 0.787 \\
\hline
\end{tabular}

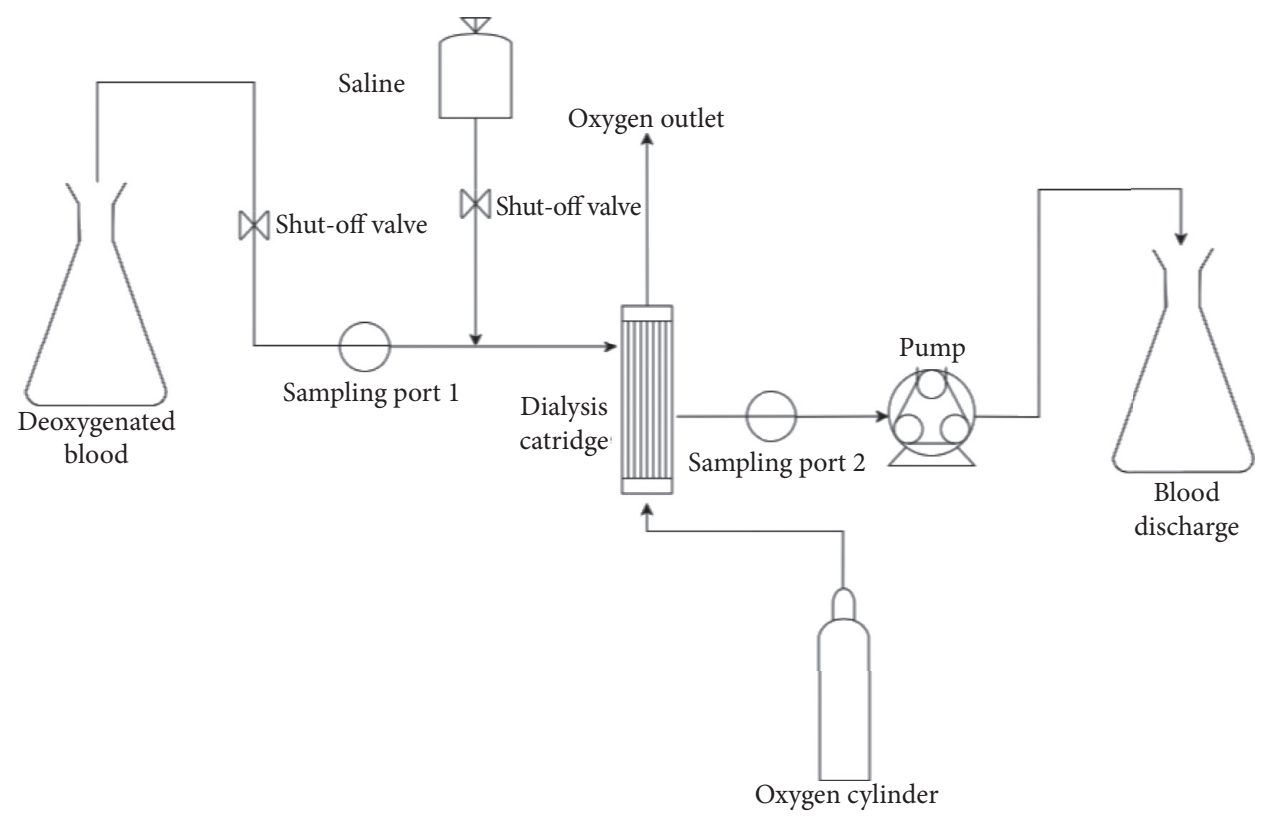

FIGURE 1: Flowsheet of the experimental setup with blood. The oxygen was passed through the dialyser via the dialysate inlet while deoxygenated blood was passed through the hollow fibers in countercurrent to the oxygen flow.

collecting flask. Oxygen was passed countercurrent at $1250 \mathrm{ml} / \mathrm{min}$ through the outside of the fibers.

The pump was placed $\approx 0.5 \mathrm{~m}$ below the base of the HFMD to achieve a pressure head, thus reducing the required suction, making sampling easier. The blood was piped through dialysis tubing fitted with inlet and outlet sampling ports (Fresenius Kabi).

After priming with normal saline, the flow was switched to blood, which was mixed by swirling, prior to and during the experiments.

Two runs were performed using a Leoceed-21N (Asahi Kasei Medical) HFMD and the third run using a Leoceed$18 \mathrm{~N}$ (effective surface area of $1.8 \mathrm{~m}^{2}$ and priming volume $96 \mathrm{ml}$ ). A high-flux Leoceed H-type dialyser was also tested, but fluid leakage across the membrane into the gas side was noted, suggesting that this high-flux dialyser may not be suitable for oxygenation.

Two to four inlet and outlet blood samples of 1-4 ml each were taken for each run with heparin-coated syringes and analysed with a blood gas analyser (Radiometer, ABL80 FLEX CO-OX) for haemoglobin concentration ( $\mathrm{Hb})$, partial pressure of carbon dioxide $\left(\mathrm{pCO}_{2}\right)$, partial pressure of oxygen $\left(\mathrm{pO}_{2}\right)$, and haemoglobin saturation (HbSat). Bicarbonate ion concentrations $\left(\mathrm{HCO}_{3}^{-}\right)$were calculated by the blood gas analyser.

Measurements were averaged for each run over the sample number. Measurement uncertainties were reported as \pm 1 standard deviation based on rounded estimates from coefficients of variation $[12,13]$ and scaled for sample number.

\section{Results}

3.1. Experiments with Water. Oxygen was passed through the HFMD at $400 \mathrm{ml} / \mathrm{min}$ and water was run countercurrent through the inside of the hollow fibers. Inlet oxygen concentration was measured at $3.61 \mathrm{mg} / \mathrm{l}$, at $37.1^{\circ} \mathrm{C}$

Outflow water was collected in beakers and oxygen concentration measured. Table 2 shows these data and corresponding calculated oxygen transfer rates.

The low reading of $28.6 \mathrm{mg} \cdot \mathrm{l}^{-1}$ is probably due to higher overall oxygen losses at saturation due to the slower flow rate.

Equation (2) is used to estimate $k_{0} A$ based on the minimum oxygen transfer rate of $14.6 \mathrm{mg} \cdot \mathrm{min}^{-1}$ at $500 \mathrm{ml} \cdot \mathrm{min}^{-1}$. Dissolved oxygen concentration is treated as negligible as haemoglobin carries most of the oxygen.

The oxygen exit stream is at atmospheric pressure, and the water inlet's partial pressure is given by the $\%$ saturation read from the dissolved oxygen meter $\times \mathrm{pO}_{2}$ in air at $84 \mathrm{kPa}$, which amounts to a difference of $\Delta \mathrm{pO}_{2}^{\text {top }}=72 \mathrm{kPa}$. The oxygen outlet pressure has little influence on the large driving force for mass transfer.

The $\Delta \mathrm{pO}_{2}^{\text {bottom }}$ requires knowledge of the unmeasured gas pressure as it enters the HFMD. The pressure regulator reading was $60 \mathrm{kPa}$, but most of the pressure drop occurs at 
TABLE 2: Minimum oxygen transfer rates calculated from differential dissolved oxygen concentrations between inlet and outflow water.

\begin{tabular}{lcc}
\hline Water flow rate $(\mathrm{ml} / \mathrm{min})$ & Dissolved oxygen in collected water outflow $(\mathrm{mg} / \mathrm{l})$ & Calculated oxygen transfer rate $(\mathrm{mg} / \mathrm{min})$ \\
\hline 50 & 28.6 & 1.25 \\
200 & $>32.9$ (out of range) & $>5.85$ \\
500 & $>32.9$ (out of range) & $>14.6$ \\
\hline
\end{tabular}

the needle valve. Also, prior to membrane contact, there was a contractor connection and the expansion/elbow entering the membrane unit, whereas on the discharge side there was just the expansion/elbow and a short length of tubing to the discharge. While it is not possible to exactly know the pressure in the membrane unit, it must be considerably lower than the regulator's pressure reading, and a simple estimate suggests that the relevant pressure drop is as low as $0.1 \mathrm{kPa}$.

Because the outlet water stream is at or above saturation, the partial pressure difference at that point is at most equal to that overpressure amount. Thus, the mass transfer coefficient calculations are highly sensitive to the actual pressure in this region.

For a $0.1 \mathrm{kPa}$ partial pressure drop across the $\Delta \mathrm{pO}_{2}^{\text {bottom }}$ and a minimum oxygen transfer rate measured at $14.6 \mathrm{mg} /$ min, equation (2) yields a $k_{0} A$ value of $1.334 \mathrm{mg} \cdot \mathrm{min}^{-1} \cdot \mathrm{kPa}^{-1}$. This implies a 3.4 -fold larger oxygen mass transfer rate than required to fully oxygenate blood to $95 \%$ saturation for incoming $\mathrm{pO}_{2}$ of $45 \mathrm{mmHg}$ and 1.7-fold larger than needed if the incoming $\mathrm{pO}_{2}$ is $25 \mathrm{mmHg}$.

Even in the unlikely case of a $\Delta \mathrm{pO}_{2}^{\text {bottom }}$ of $6 \mathrm{kPa}$, the potential mass transfer rate of oxygen will be 1.4-fold larger than the minimum needed for incoming blood with oxygen partial pressure of $45 \mathrm{mmHg}$ and $70 \%$ of the required amount for an incoming saturation of $25 \mathrm{mmHg}$.

3.2. Results for Gas Transfer in Blood. As seen in Figure 2, the dark blood entering the top and bright red blood exiting from the bottom of the HFMD is clear evidence of oxygenation.

Measurements from the inlet and outlet ports from two runs using a Leoceed-21N HFMD and one run using the Leoceed-18N HFMD are shown in Table 3. Samples ( $n=2$ to 4) were averaged and reported \pm one standard deviation measurement uncertainty.

Measurement uncertainties for the blood gas analyser were approximated as $1 \%$ for $\mathrm{pO}_{2}, \mathrm{pCO}_{2}$, and $\mathrm{Hb}$ and $0.1 \%$ for HbSat based on the reported coefficient of variation data $[12,13]$. The high values for $\mathrm{pCO}_{2}$ are in keeping with known changes in stored blood [14].

Oxygen content per $100 \mathrm{ml}$ of blood was calculated using a conservative Hüfner constant of 1.31 as follows [15]:

Oxygen content per $100 \mathrm{ml}=1.31 \cdot \mathrm{HbSat} \cdot 0.01+0.0225 \cdot \mathrm{pO}_{2}$.

Substituting the differential values for $\mathrm{HbSat}$ and $\mathrm{pO}_{2}$ between inlet and outlet into (3), the oxygen transfer rate $\left(\mathrm{VO}_{2}\right)$ in $\mathrm{ml}(\mathrm{STP}) \cdot \mathrm{min}^{-1}$ for a blood flow rate of $500 \mathrm{ml} / \mathrm{min}$ was calculated as shown in Table 4. This table also shows the percentage of the nominal $250 \mathrm{ml}(\mathrm{STP}) \cdot \mathrm{min}^{-1}$ oxygen

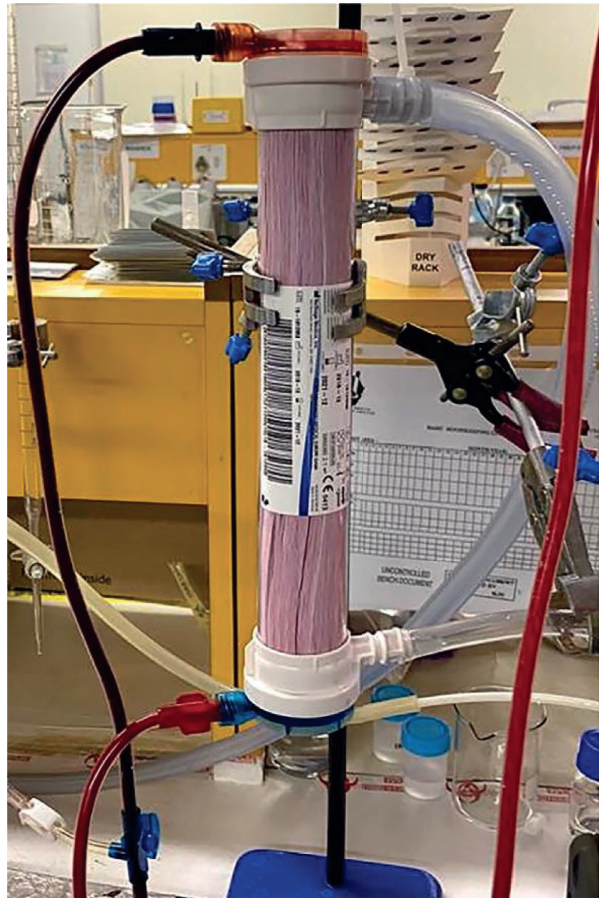

FIGURE 2: Vertically mounted Leoceed-21N HFMD showing dark deoxygenated blood entering the device at the top and bright red oxygenated blood exiting from the bottom of the device.

consumption rate $\left(\mathrm{VO}_{2, n}\right)$ and the $\%$ maximum $(100 \% \mathrm{HbSat}$ at the outlet at prevailing $\mathrm{Hb}$ ) oxygen transfer rate $\left(\mathrm{VO}_{2, \max }\right)$.

Highest oxygen transfer rates were obtained on Run 1 with the 21N HFMD. Run 2 utilising the same HFMD showed diminished oxygen transfer rates compared to Run 1 , probably due to fouling of the HFMD which was noted prior to the second run. Run 3 with the $18 \mathrm{~N}$ HFMD showed the lowest oxygen transfer rates which is consistent with the smaller surface area.

Using equation (2), the product of the mass transfer coefficient and the area $\left(k_{0} A\right)$ estimates for oxygen was 0.72 , 0.56 , and $0.69 \mathrm{mg} \cdot \mathrm{kPa}^{-1} \cdot \mathrm{min}^{-1}$ for runs 1,2 , and 3 , respectively. These estimates are in close agreement with theoretical $k_{0} A$ estimates for blood which ranged from 0.389 to $0.787 \mathrm{mg} \cdot \mathrm{kPa}^{-1} \mathrm{~min}^{-1}$. These estimates are also in keeping with the minimum estimated $k_{0} A$ of $1.33 \mathrm{mg} \cdot \mathrm{kPa}^{-1} \cdot \mathrm{min}^{-1}$ for a minimum oxygen transfer rate of $14.6 \mathrm{mg} \cdot \mathrm{min}^{-1}$ determined in the water experiments.

3.3. Mass Transfer Estimates for Carbon Dioxide. While the principal purpose of this study is blood oxygenation, $\mathrm{CO}_{2}$ elimination is also an important consideration. 
TABLE 3: Blood gas measurements at the inlet and outlet of HFMD at $500 \mathrm{ml} / \mathrm{min}$ blood flow rates over three runs. A Leoceed-21N HFMD was used for the first two runs and a Leoceed-18N was used for the third run. Measurements are reported as averages over $n$ samples \pm 1 standard deviation uncertainty.

\begin{tabular}{lccc}
\hline & $\mathrm{pO}_{2}(\mathrm{kPa})$ & $\mathrm{pCO}_{2}(\mathrm{kPa})$ & $\mathrm{HbSat}(\%)$ \\
\hline Run 1 $(21 \mathrm{~N})$ & & & \\
$\quad$ Hb $10.00 \pm 0.05 \mathrm{~g} / \mathrm{dl}$ & & & \\
$\quad$ Inlet $(n=2)$ & $4.55 \pm 0.03$ & $11.26 \pm 0.08$ & $37.35 \pm 0.03$ \\
$\quad$ Outlet $(n=2)$ & $15.60 \pm 0.1$ & $7.23 \pm 0.05$ & $94.70 \pm 0.07$ \\
\hline Run 2 $(21 \mathrm{~N})$ & & & \\
$\quad$ Hb 10.67 $0.04 \mathrm{~g} / \mathrm{dl}$ & & & \\
Inlet $(n=3)$ & $4.87 \pm 0.03$ & $8.82 \pm 0.05$ & $43.73 \pm 0.03$ \\
Outlet $(n=4)$ & $9.70 \pm 0.05$ & $6.92 \pm 0.04$ & $85.75 \pm 0.04$ \\
\hline Run 3 $(18 \mathrm{~N})$ & & & \\
Hb 11.20 $0.04 \mathrm{~g} / \mathrm{dl}$ & & & \\
Inlet $(n=4)$ & $4.20 \pm 0.02$ & $7.43 \pm 0.04$ & $42.68 \pm 0.02$ \\
Outlet $(n=4)$ & $10.23 \pm 0.05$ & $4.65 \pm 0.02$ & $91.08 \pm 0.05$ \\
\hline
\end{tabular}

TABLE 4: Oxygen transfer rates $\left(\mathrm{VO}_{2}\right)$ into blood for each of the three runs in $\mathrm{ml} \cdot \mathrm{min}^{-1}$. Also shown are the rounded percentages of the nominal oxygen consumption rates $\left(\mathrm{VO}_{2, n}\right)$ for a typical adult of $250 \mathrm{ml} \cdot \mathrm{min}^{-1}$ and the maximum oxygen transfer rates $\left(\mathrm{VO}_{2, \max }\right)$ calculated at the prevailing $\mathrm{Hb}$ for $100 \% \mathrm{HbSat}$ at the outlet.

\begin{tabular}{lccc}
\hline & $\mathrm{VO}_{2}\left(\mathrm{ml} \cdot \mathrm{min}^{-1}\right)$ & $\% \mathrm{VO}_{2, n}$ & $\% \mathrm{VO}_{2, \max }$ \\
\hline Run 1 $(21 \mathrm{~N})$ & $38.80 \pm 0.03$ & 16 & 91 \\
Run 2 $(21 \mathrm{~N})$ & $29.70 \pm 0.02$ & 12 & 75 \\
Run 3 $(18 \mathrm{~N})$ & $36.20 \pm 0.03$ & 15 & 85 \\
\hline
\end{tabular}

The outlet partial pressure of $\mathrm{CO}_{2}$ was estimated by performing a $\mathrm{CO}_{2}$ mass balance using $\mathrm{pCO}_{2}$ and $\mathrm{HCO}_{3}^{-}$, together with the oxygen flow rate of $1250 \mathrm{ml} / \mathrm{min}$.

From the $\mathrm{pCO}_{2}$ and $\mathrm{HCO}_{3}^{-}$concentrations at the inlet and outlet on each run, and treating $\mathrm{CO}_{2}$ binding to $\mathrm{Hb}$ as negligible, total $\mathrm{CO}_{2}$ concentrations were calculated as shown in Table 5. Using equation (2), $k_{0} A$ for $\mathrm{CO}_{2}$ was estimated for runs 1, 2, and 3 as 6.0, 6.6, and $19.4 \mathrm{mg} \cdot \mathrm{kPa}^{-1} \cdot \mathrm{min}^{-1}$, respectively. The 3 -fold higher value for the $18 \mathrm{~N}$ dialyser is probably due to the sensitivity of the calculation to the indirectly estimated outlet $\mathrm{pCO}_{2}$, and uncertainties in the bicarbonate concentrations which are calculated rather than directly measured by the ABL80 FLEX $\mathrm{CO}-\mathrm{OX}$.

\section{Discussion}

The minimum membrane oxygen transfer rate in the water experiments informed the decision to proceed to studies with blood.

The experiments with blood flowing at $500 \mathrm{ml} / \mathrm{min}$ yielded $k_{0} A$ values for oxygen which were in close agreement with the theoretically determined values and the measured value in the water study. This suggests that a Leoceed- $21 \mathrm{~N}$ HFMD would facilitate oxygen transfer rates of about $15 \%$ of the nominal $250 \mathrm{ml}(\mathrm{STP}) / \mathrm{min}$ adult oxygen consumption rate. Using two $21 \mathrm{~N}$ dialysers in parallel with total blood flow rates of up to $11 / \mathrm{min}$ would facilitate approximately $30 \%$ of this nominal oxygen consumption rate.
TABLE 5: Bicarbonate concentrations, partial pressures of carbon dioxide, and total carbon dioxide flow rates at inlet and outlet of HFMD at $500 \mathrm{ml} / \mathrm{min}$ blood flow rates over three runs. As outlet gas partial pressure of carbon dioxide is approximate, the small uncertainties in measurements are not shown.

\begin{tabular}{cccc}
\hline & $\begin{array}{c}\mathrm{HCO}_{3}^{-} \\
(\mathrm{mmol} / \mathrm{l})\end{array}$ & $\begin{array}{c}\mathrm{pCO}_{2} \\
(\mathrm{kPa})\end{array}$ & $\begin{array}{c}\text { Total } \mathrm{CO}_{2} \\
(\mathrm{mmol} / \mathrm{min})\end{array}$ \\
\hline Run 1 $(21 \mathrm{~N})$ & & & \\
Inlet $(n=2)$ & 11.62 & 11.26 & 7.10 \\
Outlet $(n=2)$ & 8.75 & 7.23 & 5.21 \\
\hline Run 2 $(21 \mathrm{~N})$ & & & \\
Inlet $(n=3)$ & 10.50 & 8.82 & 6.26 \\
Outlet $(n=4)$ & 8.68 & 6.92 & 5.13 \\
\hline Run 3 $(18 \mathrm{~N})$ & & & \\
Inlet $(n=4)$ & 10.03 & 7.43 & 5.87 \\
Outlet $(n=4)$ & 7.08 & 4.65 & 4.07 \\
\hline
\end{tabular}

As these studies were performed at ambient pressures $(85 \mathrm{kPa})$, operating at sea level and/or designing the system for increased pressure on the inlet gas may achieve an oxygen flux closer to $20 \%$ ( $40 \%$ with two HFMDs in parallel) of the nominal adult oxygen consumption subject to sufficient $\mathrm{Hb}$ in the blood.

Estimated $k_{0} A$ values for $\mathrm{CO}_{2}$ were at least an order of magnitude higher than the $k_{0} A$ for oxygen, suggesting that oxygenation will be rate limiting and $\mathrm{CO}_{2}$ elimination will be readily achieved [16]. $\mathrm{CO}_{2}$ elimination may even exceed its production rate, possibly requiring reduction of the fresh gas flow rate or adding $\mathrm{CO}_{2}$ to the fresh gas supply to limit $\mathrm{CO}_{2}$ losses.

\section{Conclusions}

A suitable repurposed HFMD with veno-venous access may provide a cost-effective, practical adjunct to respiratory support where ECMO is precluded.

Improvements in performance may be achievable in desperate situations by exceeding the specified maximum blood flow of $500 \mathrm{ml} / \mathrm{min}$ and increasing the gas-side pressure. However, this should be weighed against risk of damage to the unit resulting in patient harm, including air embolism.

Other considerations such as red blood cell damage, hemodynamic instability, cytokine activation, white blood cell depletion, coagulation, and bleeding are likely to be similar to those encountered in dialysis and will need to be addressed by clinicians before considering such an approach.

Dialysis pumps are costly, and presumably most are in service for renal therapy; thus, alternative low-cost pumps would be needed. However, the absence of automatic monitoring may increase risks such as undetected venous air embolisation and will require weighing the trade-offs in the face of a pandemic.

Further tests are essential to determine which HFMDs can be used for oxygentation and to establish the duration for which they can be operated before significant leakage occurs. 
Clinical implementation would also require consideration of the placement of the venous catheters, double vs. single lumens, and the need for noncollapsible catheters under higher flow rates.

This study points to the potential for HFMD repurposing as off-label blood oxygenators in dire, resource-constrained environments. Translational research with full cooperation of regulatory authorities in various jurisdictions would be needed to assess clinical utility, feasibility, and safety prior to any consideration of clinical implementation.

\section{Data Availability}

Readers interested in obtaining the raw data in Excel format should send an e-mail request to the corresponding author.

\section{Conflicts of Interest}

Dr Claudia Do Vale's clinical practice includes managing patients at Fresenius Dialysis units. The authors declare that there are no other potential conflicts of interest.

\section{Acknowledgments}

The authors are grateful to the following people who provided assistance in many different ways to bring this project to fruition: Prof. Martin Veller, Prof. Ian Jandrell, Dr. Paul Freinkel, Mr. Ravi Reddy, Mr. Andrew Saville, Ms. Dolly Mazwi, Mr. Humphrey Mbatha, Mr. David Heisi, Mr. Lebohang Koloti, and Mr. Liberty Mguni. The authors thank Fresenius Kabi for donating the dialysis tubing.

\section{References}

[1] M. Nacoti, A. Ciocca, A Giupponi et al., "At the epicenter of the Covid-19 pandemic and humanitarian crises in Italy: changing perspectives on preparation and mitigation," NEJM Catalyst Innovations in Care Delivery, 2020.

[2] C. Lyons and M. Callaghan, "The use of high-flow nasal oxygen in COVID -19," Anaesthesia, vol. 75, no. 7, pp. 843-847, 2020.

[3] M. A. Matthay, J. M. Aldrich, and J. E. Gotts, "Treatment for severe acute respiratory distress syndrome from COVID-19," The Lancet Respiratory Medicine, vol. 8, no. 5, pp. 433-434, 2020.

[4] G. MacLaren, D. Fisher, and D. Brodie, "Preparing for the most critically ill patients with COVID-19: the potential role of extracorporeal membrane oxygenation," JAMA, vol. 323, no. 13, pp. 1245-1246, 2020.

[5] G. Makdisi and I. W. Wang, "Extra corporeal membrane oxygenation (ECMO) review of a lifesaving technology," Journal of Thoracic Disease, vol. 7, no. 7, pp. E166-E176, 2015.

[6] V. Mishra, J. L. Svennevig, J. F. Bugge et al., "Cost of extracorporeal membrane oxygenation: evidence from the Rikshospitalet University Hospital, Oslo, Norway," European Journal of Cardio-Thoracic Surgery, vol. 37, no. 2, pp. 339-342, 2010.

[7] T. Yeager and S. Roy, "Evolution of gas permeable membranes for extracorporeal membrane oxygenation," Artificial Organs, vol. 41, no. 8, pp. 700-709, 2017.

[8] A. K. Evseev, S. V. Zhuravel, A. Y. Alentiev, I. V. Goroncharovskaya, and S. S. Petrikov, "Membranes in extracorporeal blood oxygenation technology," Membranes and Membrane Technologies, vol. 1, no. 4, pp. 201-211, 2019.

[9] R. M. Leach and D. F. Treacher, "The pulmonary physician in critical care.2: oxygen delivery and consumption in the critically ill," Thorax, vol. 57, no. 2, pp. 170-177, 2002.

[10] R. L. Fournier, Basic Transport Phenomena in Biomedical Engineering, Taylor \& Francis, Philadelphia, PA, USA, $4^{\text {th }}$ Edition, 1999.

[11] P. Squara, "Central venous oxygenation: when physiology explains apparent discrepancies," Critical Care, vol. 18, no. 5, p. 579, 2014.

[12] A. Gutierrez, Substantial Equivalence Determination Decision Summary Device and Instrument Template 510(k) Number: K051804. ABL80 FLEX.Food and Drug Administration, Silver Spring, MD, USA, 2005, https://www.accessdata.fda.gov/ cdrh_docs/reviews/K051804.pdf.

[13] J. M. Cooper, Substantial Equivalence Determination Decision Summary Device and Instrument Combined Template 510(k) Number: K080370. ABL80 FLEX CO-OX, Food and Drug Administration, Silver Spring, MD, USA, 2008, https://www. accessdata.fda.gov/cdrh_docs/reviews/K080370.pdf.

[14] R. S. Sousa, R. A. Barrêto-Júnior, I. K. F. Sousa et al., "Evaluation of hematologic, blood gas, and select biochemical variables in ovine whole blood stored in CPDA-1 bags," Veterinary Clinical Pathology, vol. 42, no. 1, pp. 27-30, 2013.

[15] J.-O. Dunn, M. Mythen, and M. Grocott, "Physiology of oxygen transport," BJA Education, vol. 16, no. 10, pp. 341-348, 2016.

[16] L. Gattinoni, F. Vassalli, F. Romitti et al., "Extracorporeal gas exchange: when to start and how to end?" Critical Care, vol. 23, no. 203, 2019. 